\title{
Assessment of the Erosive Wear Kinetics of Epoxy Coatings Modified with Nanofillers
}

\author{
Danuta Kotnarowska*, Michał Przerwa \\ Department of Mechanical Engineering, University of Technology and Humanities, Radom, Poland. \\ Email: *d.kotnarowska@pr.radom.pl
}

Received October $20^{\text {th }}, 2012$; revised November $25^{\text {th }}, 2012$; accepted December $3^{\text {rd }}, 2012$

\begin{abstract}
The paper presents results of investigation on the erosive wear kinetics of epoxy coatings modified with alumina or silica nanoparticles. Natural weathering caused a decrease of their erosive wear resistance. After a 3-year natural weathering, highest erosive wear resistance showed the epoxy coating modified with alumina nanoparticles.
\end{abstract}

Keywords: Polymer Coating; Nanofillers; Erosive Wear Resistance; Natural Weathering

\section{Introduction}

During their service life, polymer coatings are exposed to various environmental factors that deteriorate their protective and decorative functions. Among the exposure factors that affect polymer coatings applied on technical objects exposed to natural weathering conditions the following ones are most common: climatic factors (ultraviolet radiation, heat, humidity), aggressive media and erosive particles [1].

Erosion is the dominating wear process of polymer protective coatings of agricultural, constructional and mining equipment or facilities and occurs as a result of erosive particle impacts typical for a given environment. The erosive wear process occurs when hard particles (mineral particles, sand, dust, soil lumps, hail etc.) impact the surface of the object. Hard particles cause wear of the surface which leads to material losses in the superficial layer $[2,3,4]$. Erosive wear of polymer coatings manifests itself in abrasion, peeling, scratching, losses of their parts as well as deformation of the coating with substrate - in the places where erosive particles impact the coating. This is a complex process and its kinetics depends on particles material kind, their geometrical parameters, shape, velocity and impact angle as well as on the coefficient of friction between the coating and erosive particle. Erosive wear intensity of coatings rises with a synergetic action of heat strokes, ultraviolet radiation as well as aggressive media. Environmental factors affect elastic, frictional and strength properties of polymer coatings determining their erosive wear resistance.

Ultraviolet radiation is the most dangerous climatic

"Corresponding author. factor that causes chemical and physical destruction of polymer coatings [5,6] which, first of all, destroys superficial layers generating silver cracks. Superficial silver cracks can also propagate inside the coating. As the result of the action of ultraviolet radiation, an intensive chemical and physical destruction of coating surfaces occurs which, first of all, deteriorates coating decorative properties [7]. UV radiation induces oxidation of coating superficial layers what results in an increased brittleness. This manifests itself in a loss of cohesion between binding resin and fillers and pigments. In the next stage, pigment and filler particles are released from the coating surface layers. This process is called chalking and causes an increase of the surface roughness which, in turn, causes gloss loss and colour fading deteriorating, ipso facto, coating decorative properties. Moreover, microroughness cavities create favourable environment for the growth of microorganisms (such as viruses, bacteria and mould fungi) leading to the coating degradation in result of biological corrosion development, for instance in form of etching pits in the coating structure. Pits generated in coatings can develop and, in the final stage, they can reach the substrate and due to this the coating loses its decorative and protective properties. Deterioration of decorative properties may also result from the action of such aggressive media as: brine, marine breeze, acid rains, exploitation fluids and bird droppings [8-11]. Aggressive media induce also coating cracking and swelling as well as generate pores $[12,13]$ that deteriorate the protective effectiveness of the coating. Moreover, aggressive media trapped beneath the coating, where they accumulate, may induce blistering processes, whereas, a direct contact of aggressive media with the metal substrate 
causes the development of corrosion processes. Corrosion products formed at the substrate surface reduce or destroy the coating/metal bond what leads to the adhesion loss $[8,10,14]$.

The need to investigate kinetics of organic coating erosive wear caused by hard particles impacting results from the fact that the erosive wear process is not sufficiently recognised. Additionally, in the studies on the erosive wear kinetics of polymer coatings, the extent of coating destruction induced by environmental factors (aggresive media, ultraviolet radiation, mechanical stresses) should also be taken into consideration because the erosive wear intensity is conditioned by changeable environmental conditions [15-17].

\section{Method of Coating Sample Preparation}

Three-layer epoxy coatings (Figure 1) were applied by air-spraying on the steel substrate. The coating consisted of two primer layers (2 and 3) and one unmodified (A) or nanofiller-modified (B) surface layer.

The samples used in the investigation were made of S235JR steel and were of dimensions $160 \times 80 \times 2 \mathrm{~mm}$. The surfaces of the samples were prepared by grit blasting (in a special tumbler) with the use of small ceramic bars. Before coating application the samples were degreased.

The epoxy paint was modified with alumina nanoparticles $\left(\mathrm{Al}_{2} \mathrm{O}_{3}\right)$ with the grain size of $20 \mathrm{~nm}$ or silica nanoparticles with the size of $12 \mathrm{~nm}$. The nanofiller content was $3.5 \%$ (by weight). The obtained coatings were acclimatised for 10 days at the temperature of $20^{\circ} \mathrm{C}$ and the relative humidity of $65 \% \pm 5 \%$ (PN-EN 23270:1993).

\section{Investigation Methodology}

The coating thickness was measured with the use of

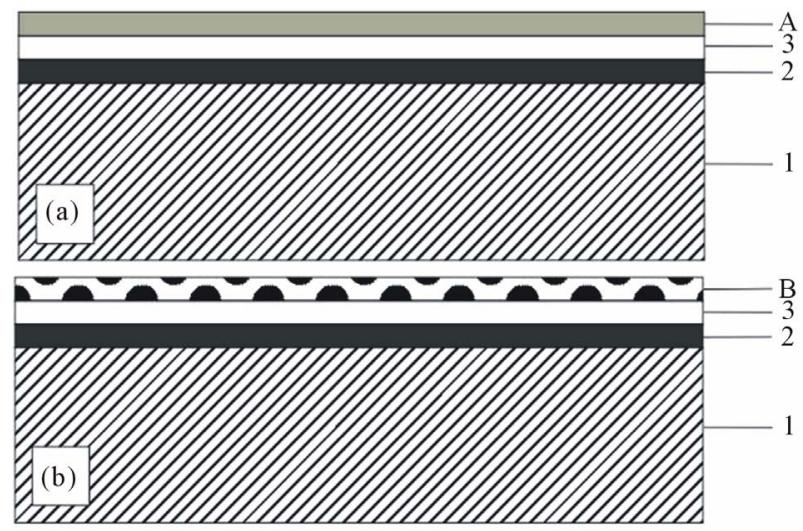

Figure 1. Cross-section scheme of the investigated epoxy coatings; (a) unmodified coating; (b) modified coating, 1steel substrate; 2-primer layer I (epoxide); 3-primer layer II (epoxide); A-unmodified surface layer; B-nanofillermodified surface layer.
Mega-Check FE meter (according to the Polish standard PN-EN ISO 2808:2000). The average thickness of the three-layer coatings was equal to $120 \mu \mathrm{m}$, including the surface layer with the thickness of $40 \mu \mathrm{m}$. The coating hardnes was determined with the application of the Buchholz method (according to the Polish standard PNEN ISO 2815:2004). For coating roughness measurements the Hommel T500 tester was applied (according to the Polish standards PN-87/M-04251, PN-ISO 8501-1:1996, PN-ISO 8501-1:1998).

\section{Methodology of the Erosive Wear Resistance Evaluation}

The resistance to erosive wear was evaluated using the falling abrasive particles method which consists in subjecting coatings to the action of abrasive material stream. The investigation on the coating erosive wear was carried out using the apparatus presented in Figure 2.

The resistance to erosive wear of polymer coatings was evaluated applying the criterion $\mathrm{S}$ according to Equation (1). It expresses a proportion of the total mass $M$ of erosive particles which erode the coating (exposing the steel substrate surface of the ellipsoid shape with the minor diameter $d=3.6 \pm 0.1 \mathrm{~mm}$ ) to the coating thickness $G$ :

$$
S=\frac{M}{G}
$$

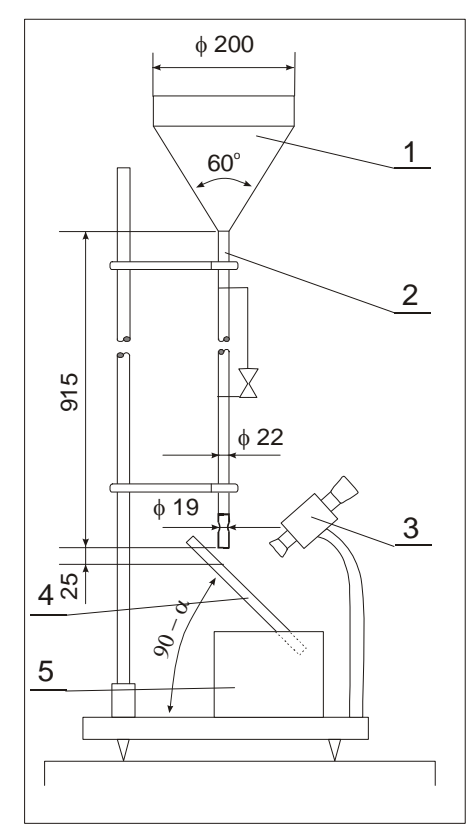

Figure 2. Apparatus for erosive wear of polymer coating testing: 1-container for erosive material; 2-pipe transporting erosive material; 3-optical microscope; 4-tilting holder for fixing metallic test specimen with examined coating; 5-container collecting erosive material after the test. 
where: $S$-erosive wear resistance, $[\mathrm{kg} / \mu \mathrm{m}] ; M$-mass of erosive particles, $[\mathrm{kg}] ; G$-average coating thickness, $[\mu \mathrm{m}]$. Particles of granulated alundum 99A (according to the Polish Standard PN-76/M-59111) of grain number 30 (according to PN-ISO 8486-2) were used as abrasive material (Figure 3). Alundum grains were of the size $0.60-0.71 \mathrm{~mm}$. The main constituent of erosive material was aluminium oxide (minimum 99\%). Other constituents were: silicon dioxide, iron oxide, calcium oxide and sodium oxide.

A sample with tested coating was inclined by $45^{\circ}$. The tests were carried out at the temperature of $20^{\circ} \mathrm{C} \pm 2^{\circ} \mathrm{C}$ and the relative humidity of $65 \% \pm 5 \%$.

\section{Investigation Results}

The effect of weathering on the epoxy coating thickness is presented in Figure 4. One may notice that coating thickness decreased on average by $2 \%$ after a 3 -year ageing period. Swelling was observed only for unmodified coatings aged for 2 years. Addition of the nanofiller favourably increased the coating structure tightness, what prevented swelling of the nanofiller modified coatings.

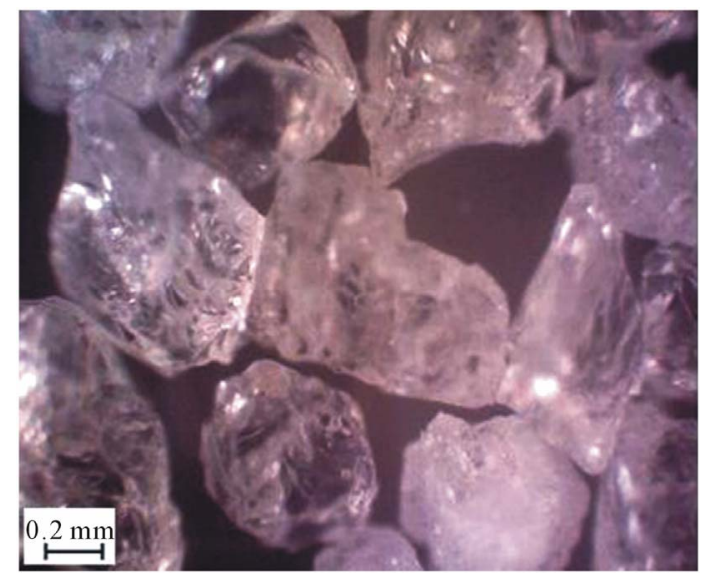

Figure 3. Morphology of alundum particles.

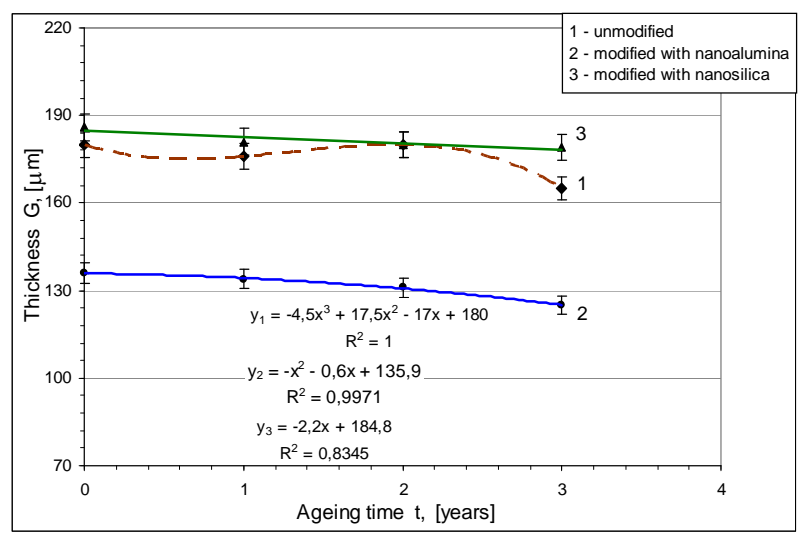

Figure 4. Thickness of epoxy coatings subjected to natural weathering conditions for 3 years.
Hardness characteristics (Figure 5) of epoxy coatings reveal an essential effect of the modification with alumina or silica nanoparticles on an increase of the unaged epoxy coating hardness. After a 3-year natural weathering only the alumina modified coatings showed increased hardness.

Results of the surface topography measurements of epoxy coatings reveal an essential effect of a 3-year natural weathering on an increase of the coating surface roughness (Figures 6 and 7). The highest $\mathrm{Ra}$ and $\mathrm{Rz}$ parameters-over the whole weathering period-were observed for coatings modified with nanosilica. Reasons of the increased surface roughness can be accounted for a tendency of silica nanoparticles to form globules. Such explanation is confirmed by the increase of $\mathrm{Ra}$ and $\mathrm{Rz}$ parameters by over $100 \%$. Positive effect of modification on the surface roughness decrease was stated for epoxy coatings with the alumina modified surface layer.

The carried out investigation on epoxy coatings, after 3 year natural weathering, showed a decrease of the resistance to alundum particles impacts. Moreover, the results of erosive wear investigation proved that modifycation of epoxy coatings with nanosilica caused a slight

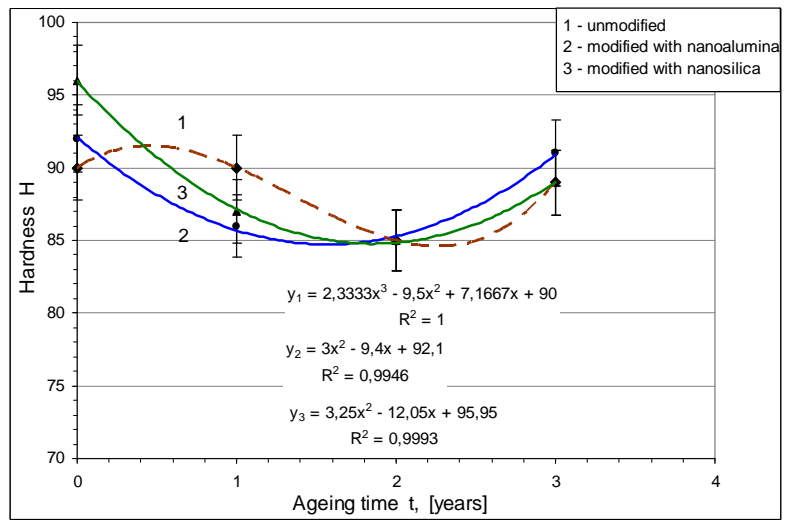

Figure 5. Hardness of epoxy coatings after 3-year natural weathering.

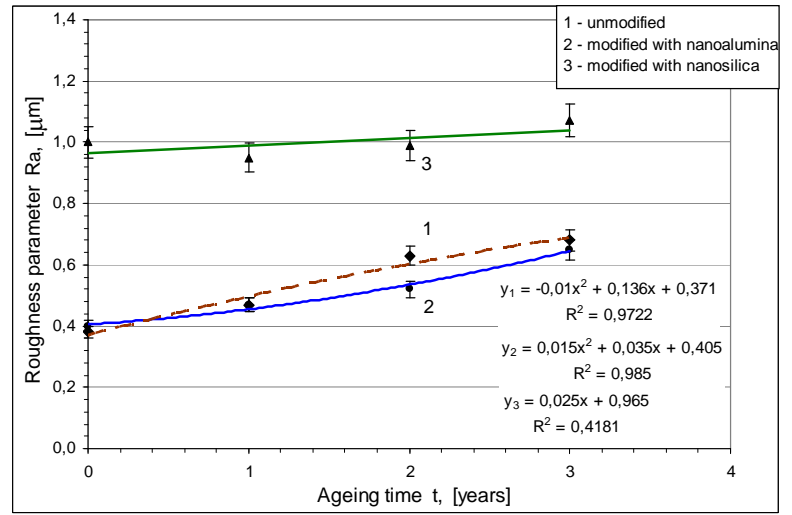

Figure 6. Effect of natural weathering on the Ra parameter of epoxy coatings. 
decrease of their erosive wear resistance (by $5 \%$ ). The erosive wear resistance of epoxy coatings modified with alumina was comparable with that of unmodified coatings (Figure 8).

The surface layer of a nano-silica modified epoxy coating showed the lowest erosive wear resistance (S) after a 3-year natural weathering (Figure 9). Its erosive wear resistance was over $12 \%$ lower compared to the unmodified surface layer. The coating modified with alumina nanoparticles showed the highest erosive wear resistance - higher by $14 \%$ than the one of the unmodified coating.

Figures 10 and 11 present the effect of natural weathering on a destruction of epoxy coating surface. As the result of weathering, coating components lose cohesion with epoxy resin and are released from coating surface layers.

\section{Conclusions}

In summary, it is concluded as follows:

1) Modification of the epoxy coating structure advantageously affected the resistance to erosive particles action of the coatings weathered naturally for 3 years only

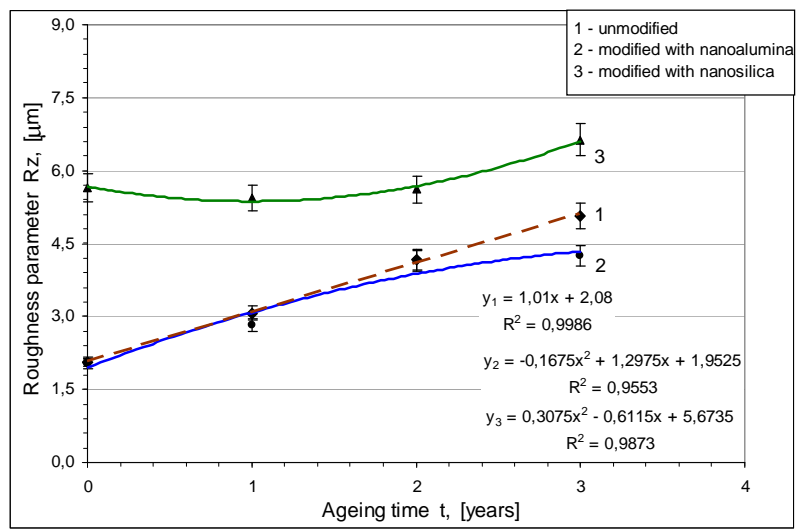

Figure 7. Effect of natural weathering on the Rz parameter of epoxy coatings.

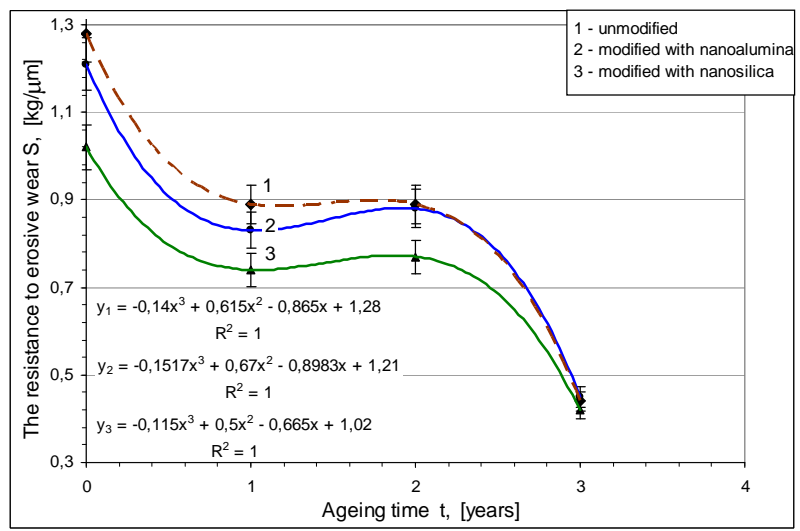

Figure 8. Erosive wear resistance of unmodified and modified epoxy coatings.

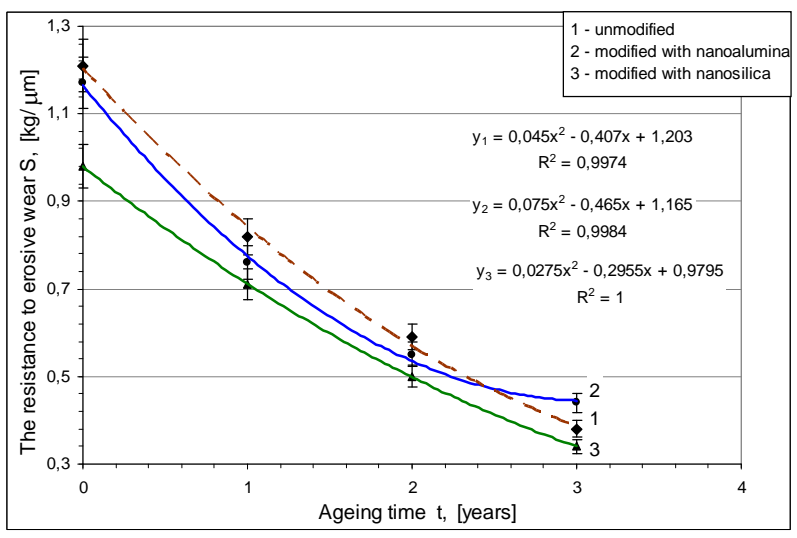

Figure 9. Erosive wear resistance of the surface layers of unmodified and modified epoxy coatings.
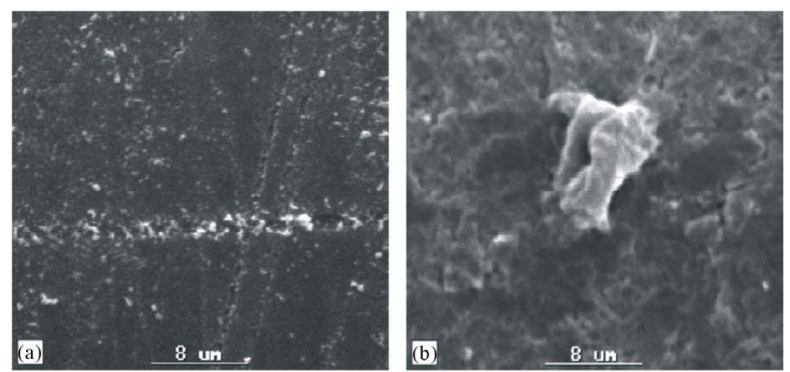

Figure 10. Surface morphology of the epoxy coating modified with alumina nanoparticles: unaged (a) and subjected to natural weathering conditions for 3 years (b).
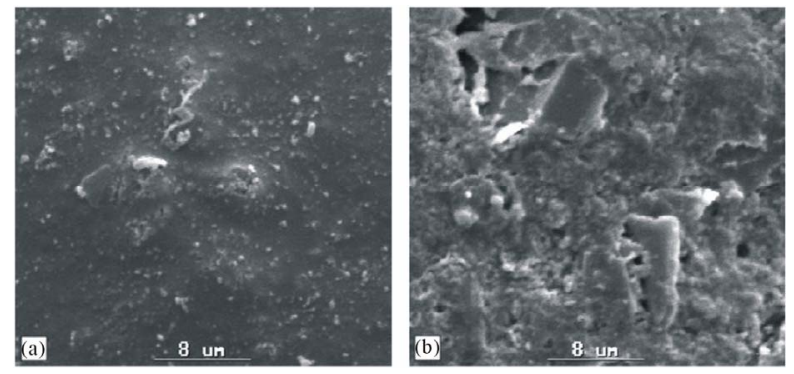

Figure 11. Surface morphology of the epoxy coating modified with silica nanoparticles: unaged (a) and subjected to natural weathering conditions for 3 years $(b)$.

in the case of alumina nanoparticles application.

2) This is due to increased hardness of the nano-alumina modified coatings and their lower surface roughness compared to the unmodified coating.

3) Modification of epoxy coatings with nano-silica resulted in lowering of the coating erosive wear resistance during the whole 3 -year weathering period. It resulted from decreased hardness and increased surface roughness of this type of coatings. Reasons of the increased surface roughness of the nano-silica modified coatings can be accounted for a tendency of silica nanoparticles to form globules.

4) Moreover addition of a nanofiller, both silica and 
alumina, favourably increased the coating structure tightness, what prevented humidity swelling of the nanofiller modified coatings. Swelling was observed only in the case of unmodified coatings after 2-year weathering period.

5) Summarising, one can state that modification of epoxy coatings with nanofillers resulted in an increased in-service durability only in the case of modification with alumina nanoparticles.

\section{REFERENCES}

[1] D. Kotnarowska, "Influence of Ageing on Mechanical Properties of Epoxy Coatings," Advances in Corrosion Protection by Organic Coatings, Cambridge, 1999, pp. $1-10$.

[2] D. Kotnarowska, "Influence of Ultraviolet Radiation on Erosive Resistance of Modified Epoxy Coatings," Solid State Phenomena, Vol. 113, 2006, pp. 1045-1052. doi:10.4028/www.scientific.net/SSP.113.583

[3] D. Kotnarowska, "Kinetics of Wear of Epoxide Coating Modified with Glass Microspheres," Progress in Organic Coatings, Vol. 31, No. 4, 1997, pp. 325-330. doi:10.1016/S0300-9440(97)00090-8

[4] D. Kotnarowska and M. Wojtyniak, "Influence of Ageing of Mechanical Properties of Epoxy Coatings," Solid State Phenomena, Vol. 147-149, 2009, pp. 825-830. doi:10.4028/www.scientific.net/SSP.147-149.825

[5] D. Kotnarowska, "Influence of Ultraviolet Radiation and Aggressive Media on Epoxy Coating Degradation," Progress in Organic Coatings, Vol. 37, No. 3-4, 1999, pp. 149159. doi:10.1016/S0300-9440(99)00070-3

[6] C. Decker and M. Balandier, "Degradation of Poli(Vinyl Chloride) by U.V. Radiation-I. Kinetics and Quantum Yields," European Polymer Journal, Vol. 18, No. 12, 1982, pp. 1085-1091. doi:10.1016/0014-3057(82)90209-9

[7] C. Decker and S. Biry, "Light Stabilization of Polymers by Radiation-Cured Acrylic Coatings," Progress in Organic Coatings, Vol. 29, No. 1-4, 1996, pp. 81-87. doi:0.1016/S0300-9440(96)00630-3
[8] T. Nguyen, D. Bentz and E. Byrd, "Method for Measuring Water Diffusion in a Coating Applied to a Substrate," Journal of Coating Technology, Vol. 67, No. 844, 1995, pp. 37-46.

[9] D. Kotnarowska, "Epoxy Coating Destruction as a Result of Sulphuric Acid Aqueous Solution Action," Progress in Organic Coatings, Vol. 67, No. 3, 2010, pp. 324-328. doi:10.1016/j.porgcoat.2009.10.026

[10] T. Nguyen, J. B. Hubbard and J. M. Pommersheim, "Unified Model for the Degradation of Organic Coatings on Steel in a Neutral Electrolyte," Journal of Coatings Technology, Vol. 68, No. 855, 1996, pp. 45-56.

[11] D. Kotnarowska, "Influence of Mechanical Factors on Surface State of Acrylic Coatings with Nanofillers," $M a-$ terials Science, Vol. 14, No. 4, 2008, pp. 347-340.

[12] P. A. Webb, "An Introduction to the Physical Characterization of Materials by Mercury Intrusion Porosimetry with Emphasis on Reduction and Presentation of Experimental Data," Micromeritics Instrument Corparation, Norcross, 2001.

[13] S. P. Rigby, R. S. Fletcher and S. N. Riley, "Characterization of Porous Solids Using Integrated Nitrogen Sorption and Mercury Porosimetry," Chemical Engineering Science, Vol. 59, No. 1, 2004, pp. 41-51. doi:10.1016/j.ces.2003.09.017

[14] T. Nguyen, D. Bentz and E. Byrd, "A Study of Water at the Organic Coating/Substrate Interface," Journal of Coatings Technology, Vol. 66, No. 834, 1994, pp. 39-50.

[15] M. Lonyuk, M. Bosma, A. C. Riemslag, J. Zuidema, A. Bakker and M. Janssen, "Stone-Impact Damage of Automotive Coatings: A Laboratory Single-Impact Tester," Progress in Organic Coatings, Vol. 58, No. 2-3, 2007, pp. 241-247. doi:10.1016/j.porgcoat.2006.09.032

[16] D. Kotnarowska, "Examination of Dynamics of Polymeric Coatings Erosive Wear Process," Materials Science, Vol. 12, 2006, pp. 138-143.

[17] D. Kotnarowska, Monograph No. 134, Radom Technical University, Radom, 2009, (in Polish). 